\title{
Historia cultural de un libro popular. Las reescrituras de la Historia de Pierres de Provenza y la linda Magalona
}

Situados entre la tradición oral y la literatura culta, lugar de encuentro de los cuentos folklóricos y la escritura, se editaron en España un cierto tipo de libros que circularon con gran éxito en el siglo xviI. Estos libros populares, cuyo origen se encuentra en bellas ediciones renacentistas, fueron a su vez la fuente de muchos pliegos de cordel de expresión en prosa que se imprimieron el siglo siguiente bajo el nombre genérico de "historias". Entre los títulos de estos libros, generalmente anónimos, están Roberto el Diablo, Clamades y Clarmonda, Flores y Blancaflor, así como también Pierres y Magalona ${ }^{1}$. La Historia de Pierres de Provenza y la linda Magalona es uno de los relatos más enraizados en la historia literaria europea, de ahí que la proliferación de ediciones populares principalmente en Francia, España, Italia y Alemania entre los siglos XVII y XVIII sean el testimonio de su extensa y larga difusión. Incluida a menudo por la tradición crítica en el grupo de obras reunidas bajo la denominación de "libros de caballerías", quizás es más acertado considerar la Historia de Pierres de Provenza y la linda Magalona, cuya configuración narrativa es ajena a la de las novelas de caballerías, como un cuento de amor, e incluso como una breve novela de aventuras. Su singularidad, así como la del grupo de libros anteriormente mencionados, se debe sobre todo a que son el lugar de inscripción y reformulación de una amplia serie de cuentos populares, lo que posiblemente es la razón de su supervivencia a los cambios literarios, su capacidad de adecuación a nuevos contextos y exigencias culturales, y la clave de su continuado éxito editorial.

MANUSCRITOS Y PRIMERAS REDACCIONES

El origen literario de la Historia de Pierres de Provenza y la linda Magalona se encuentra en Francia, donde un número considerable de

1 Bartolomé José GallaRdo, Ensayo de una Biblioteca Española de Libros raros y curiosos (Madrid: Rivadeneyra, 1863), t. I. $\mathrm{n}^{\mathrm{Q}} 868-874$. 


\section{I B R O}

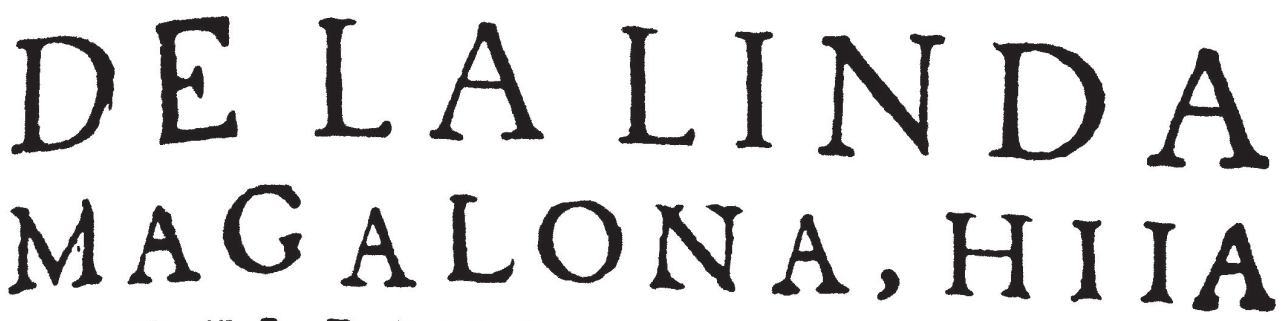

DELREY DE NAPOLES,Y

DELMVYESFORÇA.

DUCAVALLEKO PIERRES de Prouença, y de las fortunas

y trabajos que parGaron.

(?)

Pierres,

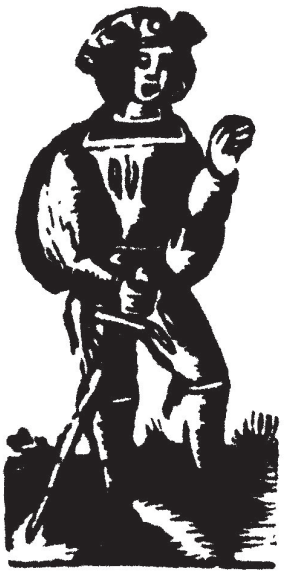

Magalona.

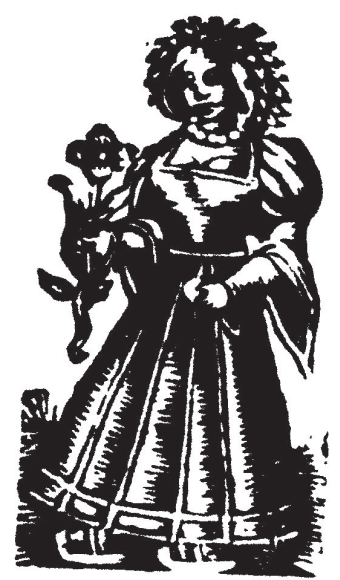

Napoles.

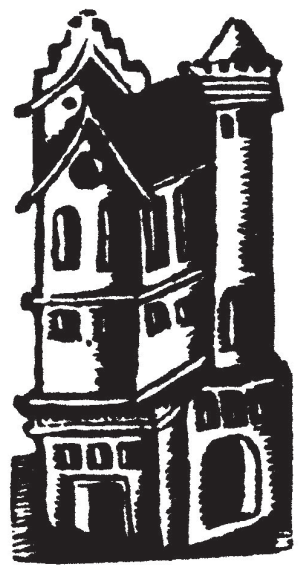

EN SARAGOCA:

\section{Impreflo con licencia en la Imprenta de Iu- lepe de Altaraque Año de M.DC.II.}

Anónimo: Zaragoza 1602, impreso por Jusepe de Altaraque, Libro de la linda Magalona. Bibliothèque Nationale de París (Rés. Y2 823). 
manuscritos sitúan las primeras redacciones del texto en la primera mitad del siglo $\mathrm{XV}^{2}$. En los manuscritos se han distinguido dos redacciones, de las cuales la más antigua, completa y correcta está representada por cuatro manuscritos franceses del siglo $\mathrm{XV}$, de los que tres se hallan conservados en la Bibliothèque Nationale de París (núm. 1501 -f. 117 al 171 verso-, núm. 1502 -f.1 al 66- incompleto, núm. 19167 nouv. acquis., -f. 244 al 303-) y en la Bibliothèque de l'Arsenal en París (núm. 3354 -f. 60 al 107-). Esta primera redacción, representada por estos cuatro manuscritos, fue el origen de los incunables franceses.

La segunda redacción es más tardía como lo prueba el incipit que la inicia, ausente en los manuscritos anteriormente comentados ( ... "et fut mis en cestuy lengaige l'an mil CCCCLiii en la matière que s'ensuyt"). Esta redacción, que posiblemente es un arreglo formal basado en un manuscrito anterior, es más corta y está retocada en la lengua y el estilo. El manuscrito de esta segunda redacción, que casi con seguridad fue la obra de un copista alemán, posee una traducción latina yuxtalineal del texto francés y numerosas glosas en alemán que testimonian la preocupación del copista por hacer más comprensible el texto a sus lectores. Este manuscrito, que se conserva en la Biblioteca Ducal de Cobourg (S. IV, 2 $)^{3}$, es el origen de las posteriores versiones alemanas.

GENEALOGÍA EDITORIAL Y CIRCULACIONES TEXTUALES EN EUROPA:

DE LOS MANUSCRITOS A LOS INCUNABLES, SUS TRADUCCIONES, HASTA LAS EDICIONES POPULARES FRANCESAS Y ESPAÑOLAS

A pesar de que la primera edición de la que con seguridad se conoce la fecha es de 1490 , existen otros incunables no fechados, anteriores a ella. Por ello señalamos como primera edición la titulada Pierre de Provence, realizada por Barthélemy Buyer hacia 1477 o 1480 en Lyon. Asimismo, ha sido destacada por la belleza de sus grabados la edición La belle Maguelonne de Guillaume Le Roy, impresa hacia $1485^{*}$. Esta edición de

2 Jean BAumel, Le livre de Maguelonne (Paris: Institut d'Etudes Occitanes, 1953).

3 Régine Collot (éd.), L'Ystoire du Vaillant Chevalier Pierre Filz du Conte de Provence et de la Belle Maguelonne. Texte du Manuscrit S IV 2 de la Landesbibliothek de Cobourg (XVème siècle) (Paris: Honoré Champion, 1977).

4 Pierre Gustave BRUNET, La France Littéraire au XVe siècle, ou Catalogue raisonné des ouvrages en tout genre imprimés en langue française jusqu'à l'an 1500 (París: A. Franck, 1865). La edición de Barthélemy Buyer está conservada en la Bibliotbèque de la Ville de Lyon (incun. 482). La edición de Guillaume Le Roy se halla en la Bibliothèque Nationale de París (Rés. Y2 361). 


\title{
Pliegos 5.
}

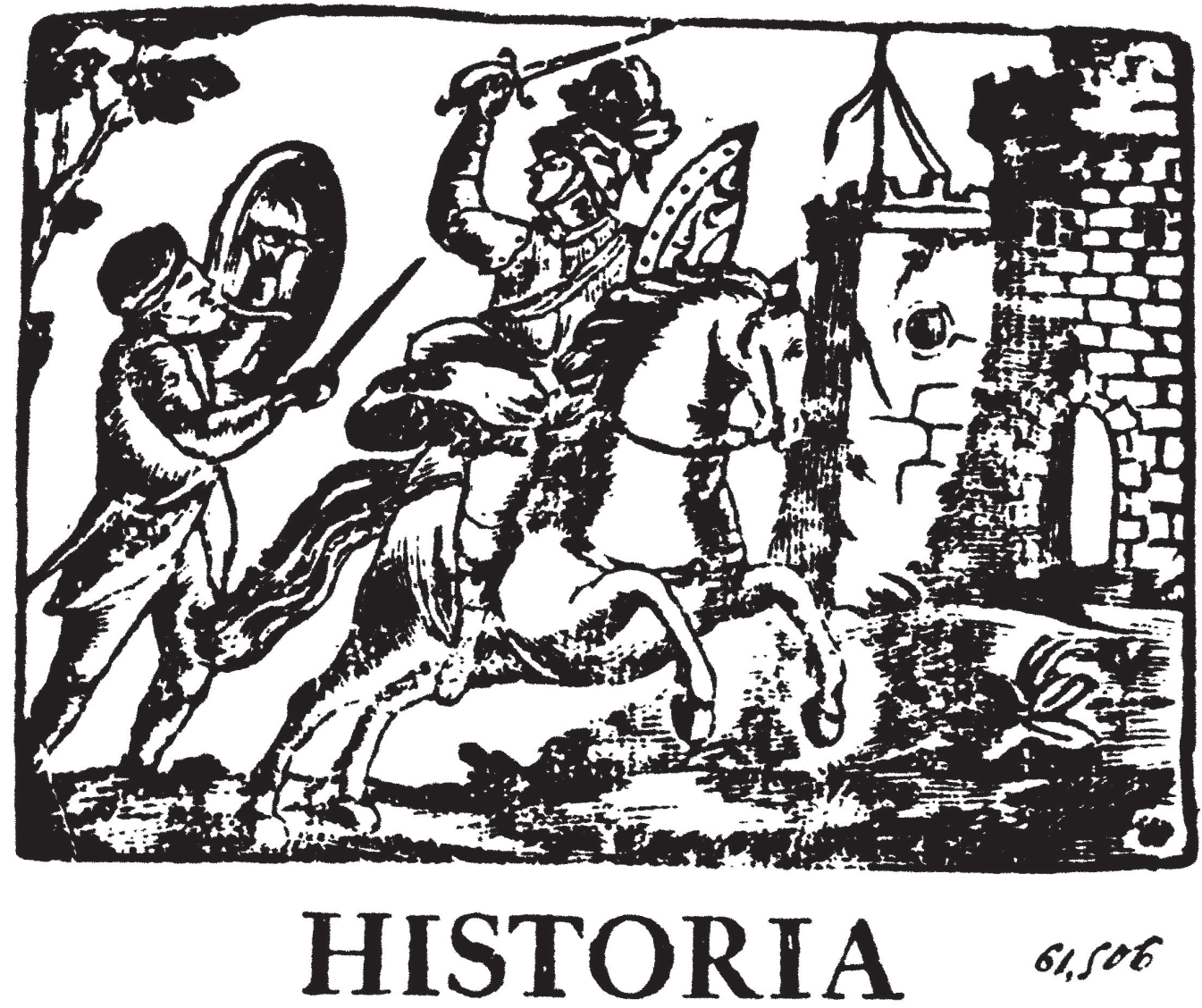

\section{DEL ESFORZADO CABALLERO}

\section{PIERRES DE PROVENZA,}

\author{
Y DE LA HERMOSA \\ MAGALONA.
}

\section{Con licencia : En Còrdoba en la Oticina de D. Rafael Garcia Rodriguez, Calle de la Librería:}

Pliego de Cordel, Córdoba, hacia 1800, impreso por Rafael García Rodríguez, Historia del esforzado caballero Pierres de Provenza. Bibliothèque Nationale de París (Rés. Y2 1052). 
Guillaume Le Roy, cuyo texto comienza con un preámbulo que no se encuentra en los manuscritos ( $\mathrm{Au}$ nom de notre seigneur jhesuchrist cy commence listoyre du vaillant chevalier Pierre, fils du comte de Provence et de la belle Maguelonne, fille du roi de Naples, ordonnée en cestuy languaige a lonneur de Dieun), sería la edición de la cual se realizó la posterior traducción española, ya que este preámbulo existe tanto en las primeras ediciones espanolas del siglo XVI como en las posteriores del siglo xVII. Son muchas las reediciones de este libro realizadas en Francia en el siglo XVI, y según G. Bollème muy pronto editores franceses especializados en libros de gran difusión, como la viuda Trepperel de París, se apropiaron del texto y contribuyeron a su éxito con gran cantidad de reimpresiones 5 . La compleja historia de este libro nos conduce hasta el editor de Troyes Nicolas Oudot, quien en los primeros años del siglo XvII añadió la Histoire de Pierre de Provence et de la belle Maguelonne al fondo de la entonces naciente Bibliothèque bleue. A partir de este momento, hasta las resumidas versiones de las ediciones del siglo XIX, realizadas por Pellerin en Epinal, el texto fue sometido a continuos cambios y modificaciones narrativas que los editores solían realizar en función de los gustos del público y que tanto caracterizaron los populares livrets de colportage franceses. Poco a poco, tanto estas ediciones populares como las adaptaciones dieciochescas de los escritores Jean Castilhon y Conde de Tressan para la colección de novelas Bibliothèque Universelle des Romans, contribuyeron a que el texto se distanciase paulatinamente de los manuscritos e incunables que lo inspiraron y atravesara varios siglos a lo largo de los cuales, aunque mantuvo su vitalidad, su trama conoció reescrituras y reelaboraciones que lo situaron cada vez más lejos de la literatura culta.

En España la fortuna de este libro es muy similar a la que obtuvo en Francia. Traducido muy pronto y fielmente de los incunables franceses, se considera la primera impresión española una edición de Burgos del 26 de julio de 1519, citada en el Registrum Colon ${ }^{6}$. El mismo año el editor de origen alemán, afincado en Sevilla, Jacobo Cromberger, editó La historia de la linda Magalona fija del rey de napoles y del muy esforçado cauallero Pierres de Prouença ${ }^{7}$, así como otras historias cortas también de origen

5 Geneviève Bolleme y Lise ANDries, Les Contes bleus (París: Montalba, 1983).

6 Antonio PALAU Y DULCET, Manual del librero bispano-americano (Madrid: Julio Ollero Editor, 1990) (1. ${ }^{2}$ ed., 1923).

7 Fechada -Año del Señor MDXIX a X del mes de Deziembre, se conserva un ejemplar en el British Museum de Londres (C.7, a 18) según F. J. NORTON, A descriptive catalogue of printing in Spain and Portugal, 1501 - 1520 (London: Cambridge University Press, 1978), n. ${ }^{\circ} 922$. 
francés de tema caballeresco o maravilloso como Partinuplés o la Historia de la linda Melosina, pequeñas ediciones in-cuarto que ya estaban destinadas a alcanzar un público muy amplio. El gran éxito del libro se prolongó en el siglo XVII, a lo largo del cual el Libro de la linda Magalona circuló en ediciones populares caracterizadas por sus rasgos formales y materiales: eran libros de bajo precio, de pequeño volumen y papel de escasa calidad, de reducido número de páginas, y en los que en la página del título era habitual el empleo de una ilustración, generalmente una xilografía, que introducía de forma general el texto. Por otro lado, la manifestación textual de estos libros les designó un espacio cultural popular: sus largos títulos, el aumento del número de capítulos con respecto al relato original, la actualización del vocabulario, los frecuentes resúmenes y recapitulaciones, la fragmentación del texto y también la simplificación de la sintaxis. Si además de todas estas particularidades de la estructura narrativa, que apuntan a la inscripción de un estilo oral en el texto impreso, consideramos la existencia de una alta tasa de analfabetismo en España entre los siglos XVI y XVII, nos permitimos pensar que con seguridad estos libros fueron leídos de manera colectiva. En este sentido, la práctica social de la lectura en voz alta, no sólo de libros populares sino también de obras cultas, fue muy frecuente en toda Europa hasta el siglo XVIII ${ }^{8}$.

Se atribuyó al prosista francés Philippe Camus la traducción al español de la Historia de la linda Magalona $y$ del esforzado caballero Pierres de Provenza, como así lo hizo el editor madrileño Francisco Sanz en la segunda mitad del siglo XvII:

Comienza la historia del muy noble y esforçado Cauallero Pierres de Prouença. Y de la linda Magalona, hija del Rey de Napoles; la cual fue sacada de la Coronica Francesa, por el honrado varon Felipe Camus, Licenciado in utroque (La Historia de la Linda Magalona, hacia 1690) ${ }^{9}$.

Esta equivocada atribución no fue sino una estrategia editorial que tenía por objetivo dar publicidad al libro, gracias a la cual se esperaba todavía una mayor difusión del mismo. Los editores se aprovecharon del

\& Margit FRENK, LLectores y oidores. La difusión oral de la literatura en el siglo de oro", en Giuseppe Bellini (ed.), Actas del Séptimo Congreso de la Asociación internacional de Hispanistas (Roma: Bulzoni Editore, 1982), pp. 101-123.

- La Historia de la Linda Magalona. Hija del Rey de Napoles. Y del esforzıdo cavallero Pierres de Provenza. Hijo del Conde de Provença, y de las fortuna ille passaron, Madrid, Francisco Sanz, hacia 1690. Simón Díaz n. ${ }^{\circ}$ 7476. Bibliothli iłle Nationale de París (Rés. Y2 851). 
éxito en España de algunas prosificaciones francesas de Camus, como por ejemplo la de Clamades et Clermonde, en España Clamades y Clarmonda, del cual el origen es el poema francés del siglo xIII Cléomadès de Adenet, y cuyo traductor español es anónimo ${ }^{10}$.

En el siglo XVIII bajo el título de la Historia del esforzado caballero Pierres de Provenza y de la bermosa Magalona, muy abreviado y alterado, el relato se imprimió como pliego de cordel. Resultado de la adaptación a versiones muy resumidas y simplificadas, esta "historia en pliegos" continuó imprimiéndose con éxito hasta el siglo XIX, a pesar de la existencia de una legislación hostil a la producción y difusión de este tipo de impresos. Estas historias en prosa, que podían contar de cuatro a siete pliegos, fueron distribuídas por la venta ambulante, de la cual las cofradías de ciegos tenían el monopolio ${ }^{11}$.

En Italia, de la Istoria memorabile e molto piacevole per ogni generoso e nobile cavaliere, del valeroso Pietro di Provenza e della bella Magbelona hay ediciones que se remontan al siglo XvI ${ }^{12}$. El libro fue especialmente conocido en el Piamonte italiano, y objeto, allí, de frecuentes reimpresiones. En Alemania y Austria el éxito de Die Schöne Magelonne también fue considerable desde fecha temprana y fue propagado en las populares colecciones de volksbücher hasta el siglo XVIII. La primera traducción en lengua alemana se habría realizado a partir del manuscrito de Cobourg a finales del siglo $\mathrm{xV}^{13}$. Para concluir este panorama, recordemos que se conocen ediciones en portugués, danés, polaco y griego.

LEYenda SOBRE la ESCRITURA y REDACCIÓn de L' HISTOIRE DE PIERRE DE PROVENCE ET DE LA BELLE MAGUELONNE

Alrededor de la redacción de esta novela anónima historiadores y críticos del siglo XIX elaboraron una leyenda que unía el relato a la parroquia de Maguelone, situada junto a Montpellier. Según esta leyenda

10 Ver José SIMÓN DIAZ, Bibliografia de la Literatura Hispánica (Madrid: CSIC, 1965), t. III, vol. 2, n. ${ }^{\circ} 7476$, y Gaston PARIS, "Romans de la table ronde, Jaufré", Histoire Littéraire de la France (Paris: Belles Lettres / Klaus Reprint, 1971), t. XXX. p. 217.

11 Jean-François BOTREL, "Les historias de colportage: essai de catalogue d'une bibliothèque bleue espagnole (1840-1936)", Les Productions Populaires en Espagne, 1850 -1920 (Paris: CNRS, 1986), pp. 25-62.

12 Alessandro d'ANCONA, Poemetti Popolari Italiani (Bologna: Zanicheli, 1889).

13 Adolphe Biedermann, Pierre de Provence et la Belle Maguelonne (Paris: Honoré Champion, 1913). 
sería el canónigo de Maguelone, Bernard de Tréviez, quien, a finales del siglo Xı, escribió este relato, quizás en provenzal, con el fin de aumentar la piedad y la generosidad de sus fieles, texto que habría sido corregido y retocado por Petrarca en el siglo XIV:

Pétrarque, dit le plus ancien historien municipal de Montpellier, Pétrarque, le père et le prince des poètes italiens, fit son cours en droit à Montpellier pendant quatre ans, comme lui-mesme le témoigne, et, pour se délasser et divertir en cette sérieuse estude, il polit et donna des grâces nouvelles, aux heures de sa recréation, à l'ancien roman de Pierre de Provence et de la belle, que Bernard de Tréviez avait fait couler en son temps parmi les dames, pour les porter plus agréablement à la charité et aux fondations pieuses ${ }^{14}$.

Una inscripción en la puerta de la iglesia de Maguelone, "B. de III VIIS fecit boc Anno Incarnationis Domini MCLXXVIII", contribuyó a la identificación de esta firma con la del autor del libro. Hubo quien consideró no sólo que la paternidad de la obra se debía a Bernard de Tréviez y la redacción ulterior a Petrarca, sino que, en el siglo XVI, Rabelais habría tenido también ocasión de intervenir en la redacción de esta historia durante su estancia en Montpellier:

Composé en vers provençaux au XIle siècle, il fut, dit-on, remanié au XIVe siècle par Pétrarque, pendant ses quatre années de séjour à Montpellier pour étudier le droit. C'est sous cette nouvelle forme qu'il nous aurait été conservé par les rarissimes exemplaires qui subsistent. On ajoute qu'il fut même rétouché au XVIe siècle par Rabelais qui sollicitait le titre de docteur à notre école de médecine ${ }^{15}$.

A pesar de esta leyenda, en la redacción de la Histoire de Pierre de Provence et de la belle Maguelonne no intervinieron ni Bernard de Tréviez, ni Petrarca ni Rabelais. El crítico G. Paris defendió el carácter anónimo de la obra y refutó definitivamente las diferentes atribuciones de paternidad de la misma, las cuales aún se mantienen en algunos catálogos bibliográficos en los que todavía aparece la mención de Bernard de Tréviez como autor de la obra:

Ce sont là de pures inventions de Pierre Gariel, auteur du livre bizarre intitulé Idée de la ville de Montpellier, qui vont de pair avec les fables de Nostradamus. Le chanoine Bernard de Tréviers a composé, à l'éloge de la ville de Maguelone, deux pièces de vers latins publiées par Gariel, dont l'une est datée de 1178 . Ce

14 Pierre Gariel, Idée de la ville de Montpellier, 1665, dans C. Fauriel, Histoire de la Poésie Provençale (Paris: Benjamin Duprat, 1846), t. III. pp. 506-507.

15 Frédéric Fabrège, Histoire de Maguelone (Paris: Picard, 1894), t. 1. pp. 65-66. 
sont ces compositions qui ont inspiré à Gariel sa fantastique histoire. Quant à Pétrarque, c'est uniquement parce qu'il a passé quatre ans, de quatorze à dix-huit ans à Montpellier que Gariel l'a mêlé à sa fiction ${ }^{16}$.

Ecos de la leyenda y del arraigo del relato en esta zona permanecen en la tradición oral provenzal, es el caso de refranes como la Bello Estello, Magalouno, que se courron après emé Peire de Prouvènçó, e tóuti li sèt an se maridon, dicho tradicional mediante el cual se explica la conjunción septenal de los planetas Venus y Saturno ${ }^{17}$. Se considera actualmente que esta novela, tan tempranamente traducida al español, habría sido escrita en el sur de Francia gracias a las numerosas referencias a localidades, como por ejemplo el hospital y la iglesia de San Pedro de la Isla de Maguelone en Montpellier. A pesar de las alusiones geográficas en la obra, la crítica ha concluído que no existiría ningún original escrito en provenzal. Por otra parte, aunque el marco histórico de la novela se sitúa en la segunda mitad del siglo XII, época en la que se produjeron alianzas entre Nápoles, Sicilia y la casa de Anjou-Provence, que de alguna manera se aluden en el argumento de este relato, en opinión de C.Nisard nada prueba que la novela esté fundada en ninguna circunstancia verdaderamente histórica ${ }^{18}$.

\section{EL CUENTO POPULAR Y SU INSCRIPCIÓN EN LOS LIBROS POPULARES}

Sin duda los libros populares son una mezcla de fuentes muy variadas e inciertas, tanto populares como cultas. Se percibe en ellos una combinación de cuentos folklóricos, textos medievales rejuvenecidos en el Renacimiento, $\mathrm{y}$, en ocasiones, de relatos inspirados en la hagiografía popular más conocida. La ausencia de un autor determinado, que facilitó las manipulaciones de los textos que ejercieron los editores, y la lectura en voz alta de los relatos a un auditorio que interviene y participa, nos hacen ver estos libros españoles del siglo XVII, y las "historias" en prosa, impresas en pliegos de cordel en el siglo XVIII, como el resultado de intercambios entre la transmisión oral y la escritura, de ahí que los textos nunca sean definitivos y también evolucionen. En la Historia de Pierres de Provenza y la linda Magalona perdura una

\footnotetext{
16 Gaston PARIS, Romania, 1889, t. XVIII. pp. 510-512.

17 Frédéric Mistral, «Magalouno", Lou Trésor Dou Felibrige. Dictionnaire ProvençalFrançais (Aix-en-Provence: Edisud, 1886), t. II. p. 244.

18 Charles NISARD, Histoire des livres populares ou de la littérature du colportage depuis le XVe siècle (Paris: E.Dentu, 1864), 2ème. éd., t. Il. pp.: 411-415.
} 
fascinación por lo maravilloso, una serie de cuentos procedentes de la tradición oral que han sobrevivido a las exigencias culturales de cada época gracias a su inscripción en estos libros y pliegos.

Además de la presencia de muchos motivos folklóricos, en la Historia de Pierres de Provenza y la linda Magalona es sobre todo cuestión del robo de una joya por un pájaro de presa, causa de la separación de los amantes, y del posterior descubrimiento de la misma en el cuerpo de un pez, la señal que anuncia y prepara su reunión. Con seguridad el cuento de un anillo, unido mágicamente a la vida de su propietario, es un cuento muy difundido en la tradición oral europea, según A. Aarne y S. Thompson son muchas las variantes de los cuentos-tipo $930 \mathrm{D}$ y $938 \mathrm{~B}^{19}$ :

Quando Pierres miraua y tocaba a la linda Magalona, el hallo sobre sus pechos vn cendal colorado que estaua plegado, y el con gana de saber que era aquello que estaua dentro començo lo a desplegar: y hallo dentro los tres anillos de su madre, los quales el auia dado a Magalona y ella los guardaua de buen amor. Quando Pierres los vuo visto, el los torno a plegar, y puso los cerca de si sobre vna piedra, y boluio los ojos para la linda Magalona, y mirauala de buen amor y estaua casi pasmado de amores y de plazer de manera que le parecia que estaua fuera de si, mas como sea cosa cierta que en este mundo no hay plazer sin dolor ni bien abenturança entera, vna aue de rapina pensando que aquel cendal colorado fuesse vn pedaço de carne, uino bolando y tomo aquel cendal, y fuese con el, y bolo dentro del monte y fue a posar en vn arbol muy alto ( Libro de la linda Magalona ... 1602) ${ }^{20}$.

Paralelamente a esta inscripción en la escritura, versiones de la literatura oral testimonian la vida de este cuento y su arraigo en la tradición oral moderna, como es el caso de la versión recogida por A. Larrea Palacín "el pájaro y el anillon:

... La señora había estado en un baile la noche antes, que se quitó la sortija y los anillos y los echó al joyero. Y fue María, tan de confianza como era, que fue su padre, estando podando los árboles, salió un pajarillo del árbol, cogió el anillo por el pico y se lo llevó a su nido ... ${ }^{21}$.

\footnotetext{
19 Antti AARne y Stith THOMPSON, The Types of Folktale, a classification and bibliography, FF Communications n. ${ }^{\circ} 184$ (Helsinki: Suomalainen Tiedeakatemia, 1961).

20 Libro de la linda Magalona, hija del rey de napoles, y del muy esforçado cavallero Pierres de Prouença. $y$ de las fortunas y trabajos que passaron. Zaragoza, Jusepe de Altaraque, 1602. Gallardo, I, n. ${ }^{\circ}$ 871, Simón Díaz n. ${ }^{\circ} 7472$. Bibliothèque Nationale de París (Rés. Y2 823).

21 Arcadio de LARREA PALACfN, "El pájaro y el anillo", Cuentos Gaditanos (Madrid: CSIC, 1959), pp. 115-120.
} 
Por otra parte, hemos de destacar la presencia del conocido cuento maravilloso "el anillo de Polícrates" AT 736A, cuento que aún continúa vivo en el folklore europeo y que está próximo al cuento del pez agradecido, de las Piacevoli Notti, III, 2, de Straparola. En la novela es cuestión de los tres anillos encontrados por los padres de Pierres en el cuerpo de un pez:

Acaecio un dia que los pescadores de aquella ribera del mar tomaron vn pescado muy hermoso, por su hermosura lo presentaron al conde y a la condesa los quales se lo agradecieron mucho, y asi como alguno de los criados lo destripasen en la cocina, hallaron en las tripas de aquel pescado vn cendal colorado a manera de vna pequeña pelota, y quando ellos vieron aquello, vna de las moças lo tomo y lo lleuo a la condesa, y dixole. Señora nos auemos hallado esto en el bientre del pescado. La condesa lo tomo y lo desplego con sus propias manos, y hallo dentro de aquel cendal los tres anillos que ella auia dado a su hijo quando se partio della. Quando ella los vuo mirado, conociolos muy bien, y començo a llorar (Libro de la linda Magalona ... 1602).

De este cuento, presente en todas las ediciones de la Historia de Pierres de Provenza y la linda Magalona, A. M. Espinosa nos ofrece en su colección de cuentos populares una versión en "la ahijada del diablo":

... y fue el rey y mandó llamar a Pedro y le dijo que lo iba a matar, pero que no lo mataría si le traía un anillo que se le había caído en la mar /.../ Toma este pito y te vas a la orilla del mar y lo tocas y saldrá un pececito con el anillo en la boca. Y se fue Pedro con el pito y cuando llegó a la orilla de la mar empezó a tocarlo y en seguida salió un pececito con el anillo en la boca ${ }^{22}$.

La inscripción de estos cuentos tradicionales en el texto escrito no es una característica exclusiva de la Historia de Pierres de Provenza y la linda Magalona, ya que una serie de obras literarias, anteriores al original francés, acogieron estos cuentos de tradición oral, formando un ciclo narrativo. Por otra parte, éstos cuentos seguirán siendo retomados y reproducidos posteriormente, tanto en las sucesivas ediciones del libro, que se prolongan hasta el siglo XIX, como en las diferentes reescrituras y versiones literarias que se inspiraron en la novela popular.

\section{FILIACIONES TEMÁTICAS}

El tema central de la Historia de Pierres de Provenza y la linda Magalona, la reunión de dos amantes que habían sido separados por el

\footnotetext{
22 Aurelio María EsPinosA, Cuentos Populares Españoles (Madrid: CSIC, 1946),
} vol. I, pp. 351-355. 
destino, y particularmente por causa del robo de sus anillos por un pájaro de presa que los toma creyendo que son un alimento, es un tema tradicional muy popular en Occidente desde la Edad Media, por ello un grupo de relatos de características muy similares componen un ciclo narrativo bien delimitado. En el dominio oriental este tema se desarrolla en el cuento de las Mil y una Noches la "Historia del Príncipe Camaralzaman y de la Princesa Badouze», del cual se ha considerado que, tras la expansión de cuentos orales orientales por Europa, fue la fuente de las diferentes versiones occidentales, entre las que se encuentra nuestra novela ${ }^{23}$.

Como ha demostrado C. Bremond en su estudio de la genealogía narrativa de la leyenda occidental de Plácido-Eustaquio (cuento-tipo AT 938) cuyo origen se encontraría en la antigua India ${ }^{24}$, la Historia de Pierres de Provenza y la linda Magalona es una de las versiones que la literatura profana del siglo XV ofrece de dicho cuento. Una evolución de la leyenda hagiográfica a una historia profana edificante, y luego hacia una novela de amor, se manifiesta en la introducción y el desplazamiento de una serie de motivos folklóricos. El cuento se transforma, y si en un principio era la revelación a Eustaquio de Cristo, bajo forma de ciervo, la causa de la separación de toda su familia (como ocurre en la novela española del siglo XIV El Caballero Cifar), la separación de los amantes fugitivos en el cuento de amor ya no será el imperativo religioso sino un interés tan profano como la recuperación de unos anillos.

A lo largo de la Edad Media se escriben en filigrana una serie de relatos que recogen esta variante profana del tema. La primera de estas obras es la novela del siglo XII Guillaume d'Angleterre, atribuida a Chrétien de Troyes, en la que se cuenta la historia de la separación de la familia y el robo de una bolsa de oro por un águila. En el siglo xIII, además del romance Die Gute Frau, traducción del original francés La Bone Dame, el poema de 9160 versos L'Escoufle, del autor francés Jean Renart desarrolla una intriga cuyo centro es la fuga de los amantes Guillaume y Aélis, el robo de una bolsa que contenía sus anillos por un ave de presa y su separación. Así también, la novela española El Caballero Cifar, el libro alemán Wilbeilm von Wenden y la balada inglesa Syr Isambrace, las tres del siglo XIV, son otras versiones paralelas de este cuento en las que el motivo fundamental es el repentino cambio de fortuna del héroe y la separación de su familia. En el siglo xv, un milano roba dos piedras

23 Noches 211-236 de la traducción Galland. Gédéon Busken HuET, Le thème de Camaralzaman en Italie et en France au Moyen Age.(Paris: E. Rahir, 1913) (Mélanges offerts à M. Emile Picot).

24 Claude Bremond, -La famille séparée, Communications, n. ${ }^{\circ} 39$, pp. 5-45. 
preciosas al príncipe protagonista de la historia alemana Der Graf von Savoien, como de manera similar ocurre en una versión inglesa de las Gesta Romanorum, en la novelita italiana Ottinello e Giulia, en la análoga griega Imberios y Margarone, y por supuesto en la francesa Histoire de Pierre de Provence et de la belle Maguelonne en la cual una rapaz roba a Pierre los anillos que había regalado a Maguelonne, lo cual causa la separación de los amantes.

Fuera de este ciclo se han establecido parentescos con otros cuentos de amor como Floire et Blancheflor (de rica tradición en el Romanceno español) y Aucassin et Nicolette, entre otros. Merece destacarse la novela francesa Paris et Vienne escrita en 1432 por Pierre de la Sypade, novela que también obtuvo un gran éxito y una extraordinaria difusión. En esta novela, aunque no hay ningún robo de anillos, se suceden episodios muy similares como las escenas de torneos y las citas de los amantes en el jardín propiciadas por la sirvienta-confidente de la heroína. Igualmente es un cuento de amor en el que se trata la separación y reunión de los amantes tras diversas pruebas y aventuras ${ }^{25}$.

\section{RECEPCIÓN Y REESCRITURAS EN ESPAÑA}

La novela Historia de Pierres de Provenza y la linda Magalona obtuvo un gran éxito y, como hemos visto anteriormente, muchas ediciones circularon entre los siglos xVI y xVII. En este libro se exaltan las virtudes cristianas y de hecho la heroína hace una peregrinación a Roma y funda un hospital en la costa provenzal (las fundaciones de iglesias y hospitales son desde el siglo xuI auténtico topos del sistema de valores aristocráticocristianos):

En aquella noche vino en coraçon de Magalona, pues que Pierres no era venido, que alla se pondria en vn lugar devoto por servir a Dios en el cual ella pudiese guardar su virginidad esperando si pudiese saber algunas nuevas de su muy deseado y querido amigo Pierres /.../ Magalona fue a mirar aquel lugar, el cual le plugo mucho, y de los dineros que ella tenia hizo hazer vn pequeño hospital en el qual hizo tres camas, y cerca del hospital vna Iglesia pequeña con su altar, la cual hizo llamar Sant Pedro, en remembrança de su amigo Pierres (Libro de la linda Magalona... 1602 ).

25 Werner SOderhJelm, "Pierre de Provence et la belle Maguelonne", Mémoires de la Société Néo-Philologique de Helsingfors (Helsinki: Helsingfors, 1924), vol. vir. 
A pesar de estas manifestaciones de la piedad y valores cristianos, fueron las escenas amorosas y sensuales, protagonizadas por Pierres y Magalona, la causa de los duros ataques que en el renacimiento Luis Vives expresó en su tratado De institutione christianae feminae:

Tum et de pestiferis libris, cujusmodi sunt in Hispania: Amadisus, Splandianus, Florisandus, Tirantus, Tristanus, quarum ineptiarum nullus est finis: quotidie prodeunt novae: Coelestina, laena nequitiarum parens, Carcer Amorum; in Gallia, Lancilotus à Laen, Paris et Vienna, Ponthus et Sydonia, Petrus Provincialis et Maguelona, Melusina, domina inexorabilis; in Lac Belgica, Florins et Albus Flos, Leonella et Canamorus, Curias et Floreta, Pyramus et Thisbe; sunt in vernaculas linguas transfusi ex latino quidam, velut infacetissimae Facetiae Poggii, Euryalus et Lucretia, Centum fabulae Boccatii; quos ommes libros conscripserunt homines otiosi, male feriati, imperiti, vitiis delected, nisi tam nobis flagitia blandirentur ${ }^{26}$.

Seguramente, la bien estimada en la época Historia de Pierres de Provenza y la linda Magalona fue leída por Miguel de Cervantes, a pesar de que éste atribuyera, equivocadamente, a Pierres el caballo volador que pertenecía a Clamades (de la también famosa en España Clamades y Clarmonda, novela sobre un caballo mecánico, motivo folklórico de origen oriental que también interviene en el cuento de Chaucer The Squier's tale $\mathrm{y}$ en la novela francesa del siglo xv Histoire de Valentin et Orson).

Porque ha de ser aquel mesmo caballo de madera, sobre quien llevó el valeroso Pierres robada a la linda Magalona, el cual caballo se rige por una clavija que tiene en la frente, que le sirve de freno, y vuela por el aire con tanta ligereza, que parece que los mesmos diablos le llevan. Este tal caballo, según es tradición antigua, fue compuesto por aquel sabio Merlín; prestósele a Pierres, que era su amigo, con el cual hizo grandes viajes, y robó, como se ha dicho, a la linda Magalona, llevándola a las ancas por el aire, dejando embobados a cuantos desde la tierra los miraban; y no le prestaba sino a quien él quería o mejor se lo pagaba; y desde el gran Pierres hasta ahora no sabemos que haya subido alguno en él ${ }^{27}$.

En el siglo XVII, momento de gran popularidad del libro, Lope de Vega se apropia del relato y lo reescribe como la comedia en tres actos Los Tres Diamantes, impresa en 1609 en la segunda parte de sus comedias y cuyo título hace alusión al cuento de los tres anillos robados por un ave de f. 30

26 Juan Luis VIVES, De Institutione feminae christianae Libri Tres (Bâle: 1587),

27 Miguel de Cervantes, Don Quijote de la Mancha, II parte, capítulo XI, ed. de John Jay Allen (Madrid: Cátedra, 1981), vol. 2, pp. 322-323. 
presa al protagonista, como señala Menéndez Pelayo ${ }^{28}$. Lope de Vega pone el cuento popular en boca del personaje principal en estilo romance,

\author{
Lisardo \\ ¿Qué es lo que tiene en el pecho? \\ Una colorada banda. \\ ¡Válgame Dios! ¿Qué hay en ella, \\ Que en tal sagrario se guarda? \\ Los diamantes que le dí \\ $\mathrm{Y}$ los que agora contaba. \\ No es justo que en estos pechos, \\ Donde el amor se regala, \\ Este cosa tan dura, \\ Pues hasta un mármol ablandan. \\ Sobre estas piedras los pongo; \\ Y vos, dulce esposa amada, \\ Mirad que en ese lugar \\ Sólo amor tiene posada. \\ ¡Ay, triste! Un águila vino, \\ Que bajó de aquellas hayas; \\ Imaginando que es carne, \\ El tafetán me arrebata. \\ ( Jornada primera,Los Tres Diamantes)
}

Lope de Vega reescribió con fidelidad y vigor la historia de amor original que debió leer en alguna de las numerosas ediciones de la Historia de Pierres de Provenza y la linda Magalona que circulaban en la época. Aunque Lope recuerda paso a paso todos los momentos de la novela popular, cambió los nombres de Pierres por Lisardo y el de Magalona por el de Lucinda, e incluyó algunos nuevos personajes para complicar la acción. Lope, cuya obra es fecunda en la escenificación de cuentos tradicionales, como bien ha estudiado M. Chevalier ${ }^{29}$, manteniene en este caso todos los episodios del relato y en especial aquellos que tienen su origen en cuentos folklóricos,

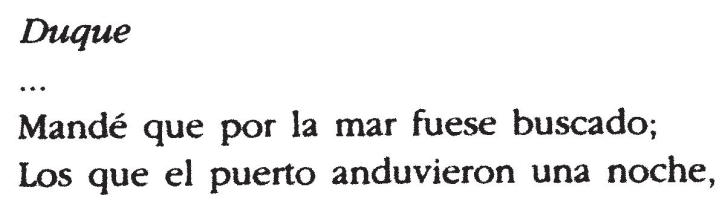

28 Félix LOPE DE VEGA, Los Tres Diamantes, ed. de 1609, Obras (Madrid: Real Academia Española, 1902), vol. XIII, ed. de Marcelino Menéndez Pelayo.

29 Maxime CHEVALIER, Folklore y literatura: el cuento oral en el Siglo de Oro (Barcelona: Crítica, 1978). 
Vieron un pez, no visto en forma y cuerpo, Porque era fiera y en extremo grande.

\section{Lucinda}

Yo estaba aquí cuando la nueva vino.

\section{Duque}

Vivió hasta agora sustentado en agua, Con algunos regalos de la tierra; Murió; hícele abrir, en cuyo vientre Pareció un tafetán con dos diamantes Que la Duquesa dio a Lisardo al tiempo Que se partió de nuestra casa a Nápoles; No puede su valor, aunque muy grande, Consolar la sospecha que me ha dado De que es muerto en la mar mi amado hijo, Pues tiene aqueste pez tan claras prendas.

(Jornada tercera, Los Tres Diamantes )

En esta versión de la Historia de Pierres de Provenza y la linda Magalona se trascienden sin duda los límites de la lectura y de la recitación oral. Los Tres Diamantes ofreció un nuevo texto, esta vez versificado, dotado de un nuevo estatuto, el de obra dramática, cambios que renovaron y ampliaron la recepción del relato.

\section{DE LA NOVELA DE CORDEL FRANCESA AL TEATRO POPULAR}

El repertorio dramático de muchas obras del teatro popular vasco está inspirado en la literatura de cordel francesa, cuyas ediciones circularon con éxito hasta finales del siglo XIX. La Bibliothèque bleue es un eslabón intermediario entre los cuentos de tradición oral y la representación teatral, Robert le diable ,Les Quatre fils Aymon, Geneviève de Bravant, Jean de Paris, o Hélène de Constantinople, son algunas pastorales que han sido representadas hasta fecha relativamente reciente y cuyo origen está en los libros de cordel franceses que llevan el mismo título. Como hemos señalado anteriormente, estos libros populares en los que se fundaron muchas piezas del teatro popular vasco, poseen a su vez una conocida procedencia folklórica. Situada dentro de esta tradición, la pastoral vasca titulada Pierres de Provence está basada en las ediciones de cordel francesas de la Histoire de Pierre de Provence et de la belle Maguelonne. 
En el texto de la pastoral vasca Pierre de Provence et la belle Maguelonne ${ }^{30}$ se reescriben en verso y se teatralizan todos los episodios del libro popular francés, a los que se añade un acompañamiento musical : el torneo de los caballeros en Nápoles, la fuga de los amantes, el robo de los anillos por un pájaro, la separación de Pierre y Maguelonne, la fundación del hospicio, la estancia de Pierre con el sultán de Argel, finalmente el reencuentro y boda de los amantes:

Pierre prend le sendal rouge et voit les anneaux:

nik eman erhastunag

Pierre pausa le sandal et aussytot un oyseau au rapina l'emporte et Pierre se leve:

ab malerouse choria! ( Pierre de Provence et la belle Maguelonne, Manuscrito f. $\left.{ }^{\circ} 17\right)^{31}$.

Aunque el comienzo está incompleto en el único manuscrito que se conserva, documento fechado a finales del siglo Xvil, subsisten al menos alrededor de 940 versos que se agrupan en estrofas de cuatro versos o cuartetos de rima asonante en los versos pares. A lo largo de las 32 hojas que lo componen se desarrolla la pastoral, cuyo texto está escrito a doble columna y en el cual se alternan el euskera y el francés. Mientras que para el euskera se reserva el texto dedicado a la recitación en la representación, todas las indicaciones escénicas o didascalias están escritas en francés ${ }^{32}$. Encuadran la obra un prólogo, escrito al revés, y un epílogo, al final del cual se lee et après tous feriont un petit tour sur le téatre avant de décendre pour aller à la dansse".

La representación se concluye con el canto de un ritual Te Deum ( "Chante le Te Deum", manuscrito f." 31 verso), como era habitual terminar las pastorales suletinas, $y$, en general, el antiguo teatro religioso europeo. En este sentido, B. Oyharçabal cita, además de Pierre de Provence, el canto de un Te Deum final en las pastorales Charlemagne, L'Enfant prodigue, Hélène de Constantinople, Ste. Elisabeth y Ste. Engrâce ${ }^{33}$.

30 Georges HERELLE, Le répertoire du théâtre tragique. Catalogue analytique (Bayonne: Courrier, 1928), p. 116.

31 Manuscrito $n .^{\circ} 18$, Biblioteca del Musée Basque de Bayonne.

32 Georges Herelle, Manuscrito n. 111 , Didascalies françaises de Pierre de Provence et la belle Maguelonne, artículo 25, f. 89 y sig. 1917, Bibliothèque Municipale de Bayonne.

33 Beñat OYharzabal, La Pastorale Souletine. Edition critique de Charlemagne (San Sebastian-Donostia: Universidad del País Vasco / Diputación Foral de Gipuzkoa, 1991). 
En lo que concierne directamente a la puesta en escena, G. Hèrelle ha destacado el empleo de dos teatros para simular el viaje que los protagonistas Pierres y Maguelonne realizaban en su fuga,

Pierres et Magalone montent à cheval devant le premier théâtre. Magalone parle à Pierre pendant le trajet, et il lui dit qu'ils sont sortis du royaume de son père, qu'ils n'ont plus rien à craindre. Puis, arrivés devant l'autre théâtre, ils mettent pièd à terre, y montent; et Magalone dit quelle est fatiguée (curieux du point de vue du moyen employé pour simuler un voyage à cheval d'un pays à l'autre) ${ }^{3+4}$.

Una lista de veinte personajes participan en la representación de esta obra, en la cual no intervienen los tradicionales satanes de las pastorales suletinas.

Paralelamente a la pastoral vasca, e igualmente producto de la amplia circulación e impacto de los libros de cordel franceses y de la apropiación y usos culturales de los que fueron objeto, son las abundantes piezas de teatro popular bretón que también se inspiraron en ellos. Acompañado de la gestualidad, música y canciones que caracterizaron estas obras y tras su versificación, el libro de cordel Histoire de Pierre de Provence et de la belle Maguelonne pasó a representarse como una pieza de teatro popular bretón en el siglo XIX. En el misterio popular bretón Mystère de Pierre de Provence et de la belle Maguelonne subsisten muchos elementos folklóricos del libro popular original. Escrita en bretón, de esta obra se conoce un sólo manuscrito que se conserva en la Bibliothèque Nationale de Paris ${ }^{35}$.

\section{CUENTO FOLKLÓRICO E HISTORIA DE UN LIBRO POPULAR}

Como hemos visto, a partir del siglo Xvir el relato de origen francés Histoire de Pierre de Provence et de la belle Maguelonne fue objeto de numerosas ediciones populares en Francia, cuyo éxito se prolongó hasta avanzado el siglo xIX. Estos libros franceses fueron el origen de las obras teatrales populares que llevan el mismo título de los repertorios vasco y bretón del siglo xIx En estas obras se transformó en verso el texto original en prosa, la intriga se enriqueció con valiosas anotaciones escénicas dirigidas a las representaciones, y, además, se adecuó el argumento a los nuevos contextos culturales vasco y bretón, argumento en el cual se conservaron los cuentos tradicionales.

34 Georges Herelle, Manuscrito n." 115, Notes sur les manuscrits de Pastorales basques qui appartiennent à Madame Campan de Sames, et qui proviennent de sa mère, Madame Latsague, artículo 51, Bibliothèque Municipale de Bayonne.

${ }^{35}$ Henri OMONT, Mystère de Pierre de Provence et de la belle Maguelonne, $\mathrm{n} .^{\circ} 36$, Manuscrits Celtiques et Basques de la Bibliothèque Nationale (Chartres: Imprimerie Durand, 1890), p. 29 (Extracto de la Revue Celtique, t. XI, 1890, pp. 389-432). 
Así también, la temprana traducción al español del incunable original francés en el siglo XVI dio paso, tras su éxito en el Renacimiento, a una importante serie de ediciones populares españolas en el siglo XViI. De estas ediciones Lope de Vega adaptó la intriga y convirtió en comedia barroca la materia novelesca, para lo cual también versificó el texto en prosa en el que se inspiró. Estos libros fueron la fuente de refundiciones en el siglo XVIII, nuevas versiones impresas como pliegos de cordel en prosa cuya difusión continuó hasta el siglo XIX.

Este relato, cuyo paso de la literatura culta a la popular se realizó tanto en Francia como en España en el siglo XVII, principalmente a causa de las particularidades de sus ediciones y las prácticas de lectura que de éstas se deducen, fue objeto de numerosas apropiaciones y usos culturales en los que se ha mantenido con vitalidad la inscripción del grupo fijo de cuentos populares que constituyen el esquema de su intriga. La reescritura de cuentos tradicionales en cada una de las nuevas versiones de la Historia de Pierres de Provenza y la linda Magalona, sin duda supone el mantenimiento, en el texto escrito, del elemento oral maravilloso, de la falta de perspectiva histórica y de profundidad psicológica en los personajes, que es propia de los cuentos folklóricos. La capacidad para adecuarse a gustos y usos diferentes de cada época y contextos culturales en los que se inscribe, hace de la Historia de Pierres de Provenza y la linda Magalona un rico lugar de intersección en el que confluyen tanto la tradición oral como la literatura culta.

Marian García COllaido

Universidad del País Vasco

El estudio del libro popular Historia de Pierres de Provenza y de la linda Magalona se realiza a través de la consideración de todas sus manifestaciones culturales, desde sus ediciones, su redacción, sus filiaciones temáticas, sus adaptaciones, su inscripción de cuentos populares, hasta el paso a libreto de teatro popular y su representación. Su rica circulación cultural ilustra el origen, producción, apropiación y evolución de los libros populares españoles del siglo XVII.

The study of the popular book Historia de Pierres de Provenza y de la linda Magalona is made across the consideration of all his cultural manifestations, from his editions, his writing, his thematic relations, his adaptations, his inscription of folktales, to the passage to popular theatre play and his representation. His rich cultural circulation explains the origin, production, appropiation and evolution of the spanish popular books at the XVII century. 